\title{
Evaluating Pedagogy and Practice of Universal Design for Learning in Public Schools
}

\author{
Lora Lee Smith Canter, Laura H. King, Jennifer B. Williams, \\ Debbie Metcalf, Katheryne Rhys Myrick Potts \\ East Carolina University
}

\begin{abstract}
How can education change to meet the demands of effectively educating an increasingly diverse student population with the skills, knowledge, and abilities they need to be productive and successful citizens in the 21st century? One possible solution is to create classrooms, teachers, and schools that embrace the progressive and inclusive practices espoused by Universal Design for Learning (UDL). In addition to being rooted in UDL pedagogy, classrooms designed to meet the challenge of 21st century education need to substantially integrate and utilize advances in technology. The vanguard of literature to date in UDL could be characterized as rhetorical advocacy. That is, UDL literature is in the early stages of introducing and promoting UDL pedagogy, but to date there is not a research base strong enough to establish UDL as a scientifically validated intervention (Edyburn, 2010). UDL might sound like a good idea, but until the research base turns the corner from advocating to assessing and measuring UDL outcomes, the promise of this approach will not be realized. This article describes a study exploring effects and outcomes of a professional development program on the perceptions and practice of UDL principles in $K-12$ public school inclusive classrooms, and could be one step toward bridging the gap from a good idea to a solidified best practice. Specifically, this study investigated a professional development program's effect on teachers' perceptions, conceptualizations, and implementation of UDL principles and practice in their classrooms.
\end{abstract}


Undoubtedly, rapid change is influencing every facet of society. Smartphones, for example, can serve as an alarm clock, find and speak directions to the nearest coffee shop, keep calendars and appointments, and provide communication options to text, see, and hear family members, friends, and colleagues almost instantly. Examples abound of the many ways that technology improves daily life. Interestingly enough, however, in the United States one of the cornerstones of society that is extremely resistant to change is education (Fullan, 2010; Hull, Balka, \& Miles, 2010; Patterson, 2010). Resistant or not, it is our research team's assertion that American education needs to heed ancient phrase, "Time and tide wait for no man" (attributed to St. Marher, 1225); and the time for this change is now. Further, the changes in society, spurred on by technological advances, are occurring at a faster rate than ever before in U.S. history. More, and faster advancing societal changes are creating situations and circumstances that will force change in American education and its foundational institutions. The forces of change are predominantly present in all of its educational institutions, but none as much as the $\mathrm{K}-12$ public schools. The changes and challenges before U.S. public schools may look slightly different in detail, but contextually they are the same. The most pressing challenges and changes facing U.S. public schools are (a) an increase in diversity in the classroom, (b) a rise in mandated movements to recognize and respect diversity and promote global awareness, (c) a push for inclusionary policies and practices, (d) a move to standardsbased curricula and increased accountability of total student achievement, and (e) an increase in access to and emphasis on technological advances.

These influences have a direct effect on what students are asked to learn and teachers to teach (Darling-Hammond, 2006; Katz, 2015; Stipek, 2002). To be better prepared for the 21 st century, all learners are asked to be critical consumers of knowledge, to think more deeply, and to use skills to be collaborative problem solvers. Gone are the days of rote, repetitive, regurgitation of knowledge. Today's teachers are charged with infusing critical thinking skills into their practice so that all students can think through the why and how of learning rather simply remembering and understanding information. As classrooms become more inclusive and diverse, a "one size fits all" approach to curriculum falls short in meeting the needs of students who are expected to be the global citizens of the 21st century (Demski, 2012; Edyburn \& Gardner, 2009; Rose \& Meyer, 2002). Additionally, teachers and students must be able to master the skills needed to manipulate the growing variety of technologies to support and extend learning.

How can education change to meet the demands of effectively educating an increasingly diverse student population with the skills, knowledge, and abilities they need to be productive and successful citizens in the 21 st century? One possible solution is to create classrooms, teachers, and schools that embrace the progressive and inclusive practices espoused by Universal Design for Learning (UDL). In addition to being rooted in UDL pedagogy, classrooms designed to meet the challenge of 21 st-century education need to substantially integrate and utilize advances in technology.

\section{UDL and Its Promise}

UDL is a learning approach that designs curricular materials, activities, and instruction with the flexibility to meet individual learners' strengths and needs so all 
students can have access to what is being learned in the class. The Center for Applied Special Technology (CAST), a nonprofit research organization dedicated to the UDL approach, defines it as:

a set of principles for curriculum development that give all individuals equal opportunities to learn. UDL provides a blueprint for creating instructional goals, methods, materials, and assessments that work for everyone - not a single, one-sizefits-all solution but rather flexible approaches that can be customized and adjusted for individual needs. (CAST, What is UDL section, 2012, para.1)

UDL is an approach rooted in deeply held educational principles and theories that have been modernized based on the influence of Universal Design, a design philosophy centred on creating equal means of access, which originated in the field of architecture. Formulated by Ron Mace, an architect and founder of the Center for Universal Design in Raleigh, North Carolina (Center for Universal Design, 2008), Universal Design is an approach for designing environments and consumer products that are accessible and usable by everyone. Even though the process of building structures is very different from educational pedagogy, this concrete ideal of engineering and building with equitable access in mind was generalized to the more abstract idea of teaching and learning with equality of learning in mind (Hall, Meyer, \& Rose, 2012). Just as UD created a way to help everyone, no matter their circumstances, to navigate and function in the physical world, UDL creates a way to help everyone, no matter their circumstances, to navigate learning.

UDL can be characterized as a proactive educational pedagogy encouraging inclusion and equitable access for all learners. Under the UDL approach, curriculum materials, activities, and instruction are designed with the flexibility to match every learner's strengths and needs so that all students can have access to what is going to be learned in the class. This approach applies as its core principles the promotion and implementation of strategies and tactics for multiple means of representation (the what of learning), expression (the how of learning), and engagement (the why of learning) to support unilateral access to learning for all students (Center for Applied Special Technology, 2015; Meyer, Rose, \& Gordon, 2014; Rose \& Meyer, 2002). The UDL framework captures ideas and theories from brain research and cognitive-social learning as well as studies of multiple intelligences and learning preferences, and combines them with its well articulated core principles to inform school leaders on ways to meet the needs of diverse learners in today's classrooms (Alnahdi, 2014; Garguilo \& Metcalf, 2015; Hartmann, 2015). The array of flexible options from the start provides each student with equal access to a wide range of learning opportunities.

Special education researchers have realized that the innovative practice of UDL holds promise in meeting the educational needs of diverse learners, and considerable research in the field has been devoted to the idea of constructing the universally designed classroom that can benefit all learners. As examples, researchers at CAST have continued to develop and refine guidelines, resources, and tools to support physical access to electronic curricula and media; and the National Center on Accessible Instruction Materials (AIM) website provides resources for parents, students, accessible media producers, and publishers. Even though there is a substantial amount of literature focusing on UDL, the vanguard of literature to date in UDL could be characterized as 
rhetorical advocacy. That is, UDL literature is in the early stages of introducing and promoting UDL pedagogy, but to date the research base is not strong enough to establish UDL as a scientifically validated intervention (Edyburn, 2010). UDL might sound like a good idea and a democratically pleasing, inclusionary, educational approach; but until the research base turns the corner from advocating to assessing and measuring UDL outcomes, the promise of this approach will not be realized.

This research study is one step toward bridging the gap from a good idea to a solidified best practice. The purpose of this article is to describe the effects of a professional development program on the perceptions and practice of UDL principles in $\mathrm{K}-12$ inclusive classrooms in public schools of a U.S. southern state. Specifically, we were interested in addressing the following research questions: (a) What was the program's effect on teachers' perceptions and conceptualizations of UDL? (b) What was the program's effect on teachers' implementation of UDL principles and practice in their classrooms?

\section{Methodology}

\section{Research Team}

A key feature of this UDL research project was the research team comprised of university faculty and public school teachers and administrators (e.g., three university faculty members, a public school exceptional children's director, and two public school special education teachers who also had professional affiliations with the university). Collaboration began in the planning and conceptualization phase, and all members of the research team were actively engaged from the inception to the conclusion of the project. The exceptional children's director had federal grant monies to provide technology tools for special education teachers to utilize in the classroom and partnered with the university to provide professional development on UDL and its practical applications to the classroom through the use of the given technology. The exceptional education teachers had positive relationships in the schools, as well as expertise in academic content, the UDL framework, and technology tools. The university had the assistive technology (AT) lab and the research expertise in UDL and research methodology.

\section{Participants}

Participants in the study were selected to provide a cross-section of the local education agency, with a focus on selecting inclusive classrooms whenever possible. Six schools were selected based on those who qualified for technology infusion. After we identified the schools, participants were selected through a prospective sampling procedure (i.e., school principals were asked to identify willing participants). This pool of participants was then personally contacted by a research team member, who explained the project and its potential benefits and addressed any questions and concerns. Participants were chosen based on their voluntary willingness to be involved in this research endeavor and signed necessary consent forms. There were eleven classrooms across the six schools who participated in the study: three elementary classrooms, four middle school classrooms, and four high school classrooms (Table 1). 


\section{Table 1}

Participating Settings

\begin{tabular}{|c|c|c|c|}
\hline School Level & Type of Setting & $\begin{array}{c}\text { Teaching } \\
\text { Model }\end{array}$ & Content Area \\
\hline Elementary Inclusion* & 4 th grade & Co-teach & English/Language Arts, Math \\
\hline Elementary Inclusion & 2nd grade & Co-teach & English/Language Arts \\
\hline Elementary Resource & 1st-3rd grade & Resource & English/Language Arts \\
\hline Middle School Inclusion 1 & 7th grade inclusion & Co-teach & English/Language Arts \\
\hline Middle School Inclusion 2 & 7th grade inclusion & Co-Teach & English/Language Arts \\
\hline Middle School Adapted & 6th-8th grade ESE & Self-contained & English/Language Arts \\
\hline Middle School B** & 6th-8th grade ESE & Self-contained & English/Language Arts \\
\hline High School Inclusion 1 & 10th grade inclusion & Co-teach & Math \\
\hline High School Inclusion 2 & 11th grade inclusion & Co-teach & English/Language Arts \\
\hline High School Adapted 1 & 10th-12th grade ESE & Self-contained & English/Language Arts \\
\hline High School Adapted 2 & 10th-12th grade ESE & Self-contained & English/Language Arts \\
\hline
\end{tabular}

This cross-selection of schools and classrooms allowed for each level to be available for comparison in the study. It provided for six co-teaching teams, one special education resource setting, and four special education self-contained settings. Initial participants for this study were seventeen public school educators in six local area schools. There were two elementary general educators and three special educators. There were two middle school general educators and four special educators. There were two high school general educators and four special educators. Participants were grouped in teams of three at each school-a general educator, a special educator in the general curriculum, and a special educator in the adapted curriculum for each school-for all but one elementary school. During the implementation of the study, three participants dropped out: two participants from an elementary co-teaching setting withdrew due to one of the teachers relocating outside the county, and one middle school teacher withdrew due to time constraints. This left 14 of the original 17 participants to complete the study.

\section{Timeline of the Study}

The study took place across one and a half academic years. In the fall semester, the participants gave consent to participate, completed the pre-survey on knowledge and perceptions of UDL, and allowed baseline observations of their instructional practices by the research team. Through the latter part of the fall semester and into the spring semester, the integration of the technology and implementation of the professional development sessions took place. In the fall of the following academic year, the post observations and interview were completed. The study focused on (a) changes in teacher knowledge and perceptions of UDL and (b) changes to instructional practices, including the use of technology in teaching. While the observations took note of student engagement in the 
observed lessons, it did not address student achievement. Therefore, the change in student population for the final part of the study was not considered to be problematic.

\section{Procedures and Data Collection}

A mixed methods research design was selected to concomitantly address educators' perceptions of UDL and observation of teachers' practices in relation to the implementation of UDL principles, with emphasis on using the technology tools that were provided. Primarily, this research project consisted of three distinct research methods (survey, direct observation, and interviewing) occurring throughout three phases (initial, implementation, and post-intervention). Each of the participants and research team members was engaged throughout all phases of the study. Further, the leadership team members and the remaining 14 participants remained the same, with the same roles and responsibilities for the study and in their professional positions.

The initial phase of the study consisted of two primary parts: (a) creating and administering a survey instrument measuring teachers' knowledge of and perceptions of UDL prior to professional development sessions and integration of the technology, and (b) conducting baseline observations in each of the settings to record the presence and utilization of UDL technologies and practices prior to the intervention of professional development and technology infusion. The pre- and post-survey, designed by the research team, was structured to allow survey participant responses to show range of understanding and/or agreement, open-ended responses for definitions, and level of proficiency on technology. The range of response options permitted a deeper understanding of participant levels of knowledge and of their perceptions about UDL and technology specific to the study. All questions were rooted in current UDL research (see, for example, CAST, 2015), The survey was developed specifically for teachers to be able to respond from their classroom perspective, as opposed to responding through a theoretical lens. The pre and post surveys were administered electronically through a Qualtrics survey platform and collected demographic information. Due to the low number of participants in the study and the need to identify pre to post submissions, the surveys were not anonymously submitted. The survey remained the same from pre to post administration in order to analyze change in perceptions and growth in knowledge.

The observation instrument was developed by the team using the UDL GuidelinesEducator Checklist Version 2 (2011). The instrument was designed to document observations of UDL practices, as well as to document the use of the embedded technology. In addition to the checklist, we took copious field notes during the observations, which were then transcribed and analyzed qualitatively for themes across participant observations. Three observations were completed pre- and post-intervention by a minimum of two different researchers to enhance reliability of the observations. Three baseline observations were conducted in each setting over a period of three weeks by at least two different members of the research team. All observers used a researchstudy-specific checklist to record their observations.

During the implementation phase of the study, the study's intervention was conducted in the form of four professional development workshops in the Assistive Technology Center on the university campus. Each session was conducted by the same 
two presenters (members of the research team). The time was divided between theory and practice: Presenting, discussing, and reinforcing the underlying theoretical constructs and principles of UDL was followed by presentation, training, and practice with a piece of technology that participants would then receive to take back to their schools to use in their classroom. In Session 1, the professional development focused on the introduction of UDL principles and framework. It also incorporated technology training on the SMART Board interactive whiteboard, its software (SMART Notebook), and associated document camera. In Session 2, the UDL framework was reviewed while participants shared specific examples of how they began integrating UDL principles into their instruction. Presentation and discussion topics for this session also included similarities and differences between UDL and Differentiated Instruction, as well as between accommodations and modifications. Session 3 began with team participant presentations showing concrete examples of how they were infusing the SMART technology and UDL framework in their instructional practices. In addition, technology demonstration and training was provided on Inspiration software, Wordle web-based software; Texthelp's Read\&Write Gold, digital text, Intel Reader, and SMART Response. In Session 4, trainers and participants continued to share examples of how they were using the technology in their classrooms, as well as to share other available resources supportive both of the infusion of UDL principles and of the technology that was provided, specifically targeting SMART Notebook extension ideas.

Following the professional development sessions, participants planned lessons through a UDL framework that incorporated the technology received from the professional development sessions. As noted above, beginning with Session 2 the participants were given time to share the implications of integrating UDL principles into their teaching, as well as to discuss what they and their students were doing with the technology they were received. Also during the implementation stage, the participants received support through the two members of the research team who worked for the school system. This support included assistance with setting up, learning, and using technology hardware and software, brainstorming UDL ideas for instruction, and troubleshooting the use of the technology to meet the needs of students and content.

During the post-intervention stage, research team members completed post observation visits to observe and record integrated technology use and UDL practices in the applied settings. Participants were again observed three times by at least two different researchers using the standardized observation recording form. Approximately $20 \%$ of the observations were simultaneously observed by two researchers for inter-rater reliability. Following the final professional development session, participants were given the post survey measuring their knowledge and perceptions of UDL pedagogical aspects and practices.

In addition, after completing post surveys and observations, all participants were interviewed about the intervention and study at its conclusion. The post interview structure was developed as a standardized format with semi-structured questions to allow for open-ended responses by the participants. Interviewers were the research team members, which allowed for a collegial conversation within the scope of the questions and were conducted with all the members of individual school team participants. All researchers conducting interviews used standard protocols and queried participants from 
the same semi-structured interview protocol. The participant responses were recorded and the interviews transcribed by a graduate student assigned to the research study but otherwise uninvolved in any of the actual research activities. The recorded responses were then qualitatively analyzed and coded for themes.

\section{Results}

\section{Survey}

Prior to the first professional development session and after the last session, participants completed a 27-item pre-test and post-test survey in Qualtrics. The survey included three sections: (a) Instructional Practices, a section of Likert-scale items, which asked participants to rate their level of agreement on ten statements regarding instructional practices, experience and training with UDL; (b) Experiences with UDL, three questions that allowed open-ended responses based on their current knowledge and experience with UDL, including one question regarding their definition of diversity in the context of education; and (c) Technology Integration, a Likert-scale section for rating their level of skill with integrating specific types of technology into teaching.

Quantitative data for this study were analyzed using SPSS 22.0 to compare means. Paired sample t-tests for means determined whether there was a difference as a result of the program. The means, standard deviations, and $t$ statistics for each survey section are presented in Table 2 and Table 3.

Table 2

UDL Pre-test/Post-test Paired Samples Statistics

\begin{tabular}{lcccccc}
\hline & \multicolumn{3}{c}{ Pre-test } & \multicolumn{3}{c}{ Post-test } \\
& $\boldsymbol{n}$ & $\boldsymbol{M}$ & $\boldsymbol{S D}$ & $\boldsymbol{n}$ & $\boldsymbol{M}$ & $\boldsymbol{S D}$ \\
\hline Instructional Practices & 14 & 14 & 1.18 & 14 & 13.9 & 3.12 \\
Experiences with UDL & 14 & 3.21 & 1.63 & 14 & 5.71 & .611 \\
Technology Integration & 14 & 7.07 & 3.12 & 14 & 10.86 & 4.42 \\
\hline
\end{tabular}

Table 3

UDL Pre-test/Post-test Paired Samples T-Test

\begin{tabular}{llcccl}
\hline & $\boldsymbol{n}$ & $\boldsymbol{M}$ & $\boldsymbol{S D}$ & $\boldsymbol{t}$ & \multicolumn{1}{c}{$\boldsymbol{p}$} \\
\hline Instructional Practices & 14 & .07 & 3.17 & .08 & .93 \\
Experiences with UDL & 14 & 2.5 & 1.74 & 5.37 & $.000^{* *}$ \\
Technology Integration & 14 & 3.79 & 3.79 & 3.74 & $.002^{* *}$ \\
Total & 14 & 6.21 & 4.54 & 5.12 & $.000^{* *}$ \\
\hline
\end{tabular}

** $p<.01$ 
Based on the paired t-test results, there was no difference in the level of agreement on statements about instructional practices between the pre-test and the post-test survey. However, there is evidence $(t=5.37, p=.000)$ that the participants agreed the intervention provided familiarity with UDL, sufficient training in UDL, and increased their implementation of the UDL approach in teaching. The survey also provided evidence $(t=-3.74, p=.002)$ that participants agreed that their level of skill integrating technology increased.

Qualitative analysis of open-ended responses indicated the following: In being able to identify the three principles of UDL (multiple means of representation, engagement, and expression), there was an increase from $29 \%(n=4 / 14)$ to $93 \%(n=13 / 14)$; the post definitions of UDL provided by participants centred on maximizing student learning and potential, meeting the needs of all learners, and making the curriculum accessible; and, when asked to define diversity, all post responses targeted the concept of recognizing differences (e.g., background, learning needs) as they relate to the instructional setting.

Also indicated on the post-test survey, participants reported an increase in providing better access to the curriculum in the general curriculum setting through their teaching approaches for students with developmental or cognitive delays. Participants indicated they felt successful in teaching students with diverse needs, including students with disabilities and those with academic giftedness. Furthermore, the majority of participants reported they were now familiar with UDL, received sufficient training, and were better able to implement a UDL approach in teaching. As far as specific technology integration, all participants rated themselves as basic to proficient in using the SMART Board and all participants used the Clicker Response System in some capacity by the end of the project. The use of other types of technology varied based on the instructional content, setting, and student needs.

\section{Observation of Instructional Practices}

With minimal numbers of participating settings at each level of educational programming (elementary inclusion or resource; middle school inclusion, resource or self-contained; and high school inclusion or self-contained), it is important to reiterate that results are not comparable, nor generalizable. Having stated that, results of the pre and post observations indicate that an increase in technology use and an increase in the use of observable UDL practices varied across these settings (see Table 4).

Demonstrating the highest increase in the use of technology were four out of five inclusion settings (Elementary Inclusion, MS Inclusion 2, and HS Inclusion 1 and 2 in Table 4) measuring an increase from $70.8 \%$ to $140.8 \%$ from pre to post observation. The other inclusion setting (MS Inclusion 1, Table 4) held the highest percentage of technology use in the pre observations for inclusion settings, so a lower increase is logical given that the participants in this particular setting were already using technology in their teaching. Demonstrating the lowest increases in technology use were the adapted curriculum self-contained settings, which also scored relatively high percentages in the use of technology in the pre observation ratings. 
Table 4

Statistics of Observation of Instructional Practices

\begin{tabular}{|c|c|c|c|c|c|c|c|c|c|}
\hline Course Name & $\begin{array}{l}\text { Tech- } \\
\text { Pre }\end{array}$ & $\begin{array}{l}\text { Tech- } \\
\text { Post }\end{array}$ & Increase & $\begin{array}{l}\text { UDL- } \\
\text { Pre }\end{array}$ & $\begin{array}{l}\text { UDL- } \\
\text { Post }\end{array}$ & Increase & $\begin{array}{l}\text { Overall } \\
\text { Pre }\end{array}$ & $\begin{array}{c}\text { Overall } \\
\text { Post }\end{array}$ & Increase \\
\hline $\begin{array}{l}\text { Elementary } \\
\text { Inclusion }\end{array}$ & 0.72 & 1.23 & $70.8 \%$ & 0.81 & 0.93 & $14.8 \%$ & 0.76 & 1.08 & $42.1 \%$ \\
\hline $\begin{array}{l}\text { Elementary } \\
\text { Resource }\end{array}$ & 0.83 & 1.03 & $24 \%$ & 0.64 & 0.97 & $51.5 \%$ & 0.73 & 1.00 & $36.9 \%$ \\
\hline MS Inclusion 1 & 0.94 & 1.00 & $6.3 \%$ & 0.60 & 0.81 & $35 \%$ & 0.77 & 0.90 & $16.8 \%$ \\
\hline MS Inclusion 2 & 0.50 & 0.93 & $86 \%$ & 0.41 & 0.82 & $100 \%$ & 0.45 & 0.87 & $93.3 \%$ \\
\hline MS Adapted & 1.18 & 1.22 & $3.3 \%$ & 0.28 & 0.83 & $196.4 \%$ & 0.73 & 1.02 & $39.7 \%$ \\
\hline $\begin{array}{l}\text { HS Inclusion 1/ } \\
\text { Math }\end{array}$ & 0.49 & 1.18 & $140.8 \%$ & 0.45 & 0.67 & $48.8 \%$ & 0.47 & 0.92 & $95.7 \%$ \\
\hline $\begin{array}{l}\text { HS Inclusion 2/ } \\
\text { English }\end{array}$ & 0.44 & 0.81 & $84 \%$ & 0.66 & 0.91 & $37.8 \%$ & 0.55 & 0.86 & $56.3 \%$ \\
\hline HS Adapted 1 & 0.73 & 0.81 & $10.9 \%$ & 0.33 & 0.67 & $103 \%$ & 0.53 & 0.74 & $39.6 \%$ \\
\hline HS Adapted 2 & 0.93 & 1.06 & $13.9 \%$ & 0.55 & 0.88 & $59.9 \%$ & 0.74 & 0.97 & $31.0 \%$ \\
\hline
\end{tabular}

For UDL practices the same trend is evident in Table 4, in that the elementary inclusion setting that has the lowest increase from pre to post observation also has the highest percentage of observable UDL practices in the pre observation ratings. Adapted special education self-contained settings continue to rank noticeably lower in UDL practices than the inclusion settings, but do show a higher increase in observable UDL practices than in their increase in the use of technology.

\section{Post Interviews}

After all professional development sessions and post observations were completed, semi-structured post interviews were conducted to assess participant perceptions of UDL. Table 5 shows the topics and questions that were addressed.

Definition of UDL. The key themes that emerged among the participants in defining UDL were accessibility, technology integration, and engagement. Participants frequently stated that they became more conscious about the need to ensure that all students could access the curricular content.

Accessibility. Overall, participants agreed that $U D L$ means considering the needs of each student and differentiating instruction so that each one can access the curriculum. Some response examples for definitions that exemplify this include:

Universal Design for Learning means considering the needs of all students and trying to reach them where they are and also encourage them to go beyond using different techniques so that all kids feel that they are learning at their level.

UDL is a way to really reach everybody and not just appease people with inclusion. You see kids learn through technology. 
It's a way to think about teaching things in different ways so that diverse students can all learn.

Making information accessible to all students-breaking it down, how you deliver it, thinking about how they assimilate the information. They can show the content back to you in different ways.

A way to make your curriculum accessible to all students and make it more engaging to give every student more opportunities to be successful in your classroom.

Integration of technology. The integration of technology was emphasized in the training and frequently observed in the final observations of the participants. The interview responses indicated that they viewed technology as a tool to help reach students in different ways and make instruction more engaging. Although the word technology itself was not prominent in the actual definitions of UDL, as the interviews progressed technology was frequently mentioned as a viable means to make curriculum accessible and more engaging. One participant defined UDL as follows: "Trying to integrate more students in learning through technology - to universally use technology to engage people."

Engagement. The need for student engagement was the third theme reflected in the majority of responses. The participants consistently spoke of the need to find out what works for each student in a diverse classroom setting. Some also saw technology as a tool for engagement: "It's harder to check out when you have to click." The following definition reflects the overall feelings of all the participants regarding engagement:

When you teach in a way that everyone can take something away and have gotten something from the lesson. Universally - each student can learn and engage in the lesson. No one would be on the sidelines saying, "I can't do it" or "I'm bored."

Impact of training on working with diverse populations. Each participant was asked how they have changed their planning and implementation of instruction to meet the needs of diverse learners. Technology and planning and resources were the key themes that emerged from this interview topic.

Technology. Participants related that they were able to integrate more technology components into their instruction than ever before. Incorporating use of the SMART Board was named most frequently as a tool they were using more efficiently and in different ways. They also mentioned they were using video recording more with students to increase engagement. There were references to resource websites that included CAST.org, presentation tools such as PREZI software, and graphic-based blogs such as those at Glogster.com. Most participants said that the increased knowledge of technology resources and practice with applications had helped them plan better. One participant mentioned that this experience had made them want to explore more technology resources and collaborate with people who have content knowledge and technology skills that complement their own personal skill sets. One participant indicated that increased knowledge of technology helped her with backwards planning: "[I am] doing backwards planning more-first clarifying what they [students] need to learn and [asking] what technology can I use to teach those concepts? Technology helps me plan backwards better."

Planning and resources. Participants reported additional positive effects of the UDL framework on planning and resources. Most articulated that they now planned with 
technology and other resources in mind more than they had before. Collaborative partnerships were included as an effective resource: "Having a partner stronger in technology helped." The participants also reflected on the importance of increased awareness of their own thinking processes in relation to student needs and strengths before lesson planning, and the value of really using that information to prepare for active participation by all students in the classroom. Some participants reflected that they constantly challenged themselves to think about how they could proactively design lessons to meet the needs of diverse learning styles and learning levels using a variety of strategies, technologies, and other resources: "It challenged me to think of other ways to do something-which has been fun." One participant shared how he became more efficient in his thinking during planning:

I am looking at the students a lot more and at what their capabilities are to make sure each of them can join in the lesson in some way... Maybe prior to this I was more likely to say, "OK, this lesson will probably get more of these kids, but then I'll do another lesson to get more of the other kids," but now, I will try to join them together in one lesson so they all can benefit from the same lesson.

The infusion of UDL principles into participants' practice appeared to foster creativity and a safe atmosphere that encouraged some risk taking. Overall, participants appeared to be more willing to think "outside the box" during the project: "I'm more apt to say, 'Let's have some fun with it. If it doesn't work, we'll try it again. At least we'll try.' The students don't mind you taking a risk - it doesn't mess up their day."

\section{Table 5}

\section{Semi-Structured Interview}

\begin{tabular}{|c|c|}
\hline Topics & Sample Probe \\
\hline Definition of UDL & $\begin{array}{l}\text { Now that you have completed trainings and have had the } \\
\text { opportunity to integrate technologies that support UDL, how would } \\
\text { you personally define the term, Universal Design for Learning? }\end{array}$ \\
\hline $\begin{array}{l}\text { Impact of training on working } \\
\text { with diverse populations }\end{array}$ & $\begin{array}{l}\text { Now that you have completed professional development, how have } \\
\text { you changed your planning and implementation of instruction to } \\
\text { meet the needs of your diverse learners? }\end{array}$ \\
\hline Integration of UDL & $\begin{array}{l}\text { Discuss some examples of how you have been able to integrate } \\
\text { UDL into your classroom and teaching. }\end{array}$ \\
\hline Current supports & $\begin{array}{l}\text { What type of supports would you say are now in place for you to } \\
\text { effectively integrate UDL principles? }\end{array}$ \\
\hline Challenges & What are the challenges you face? \\
\hline Needed support/resources & $\begin{array}{l}\text { Describe the types of supports, resources, and/or materials that you } \\
\text { feel would help you to more fully integrate the UDL approach to } \\
\text { teaching? }\end{array}$ \\
\hline Other issues or concerns & $\begin{array}{l}\text { Discuss any other issues or concerns that you have in relation to } \\
\text { UDL. }\end{array}$ \\
\hline
\end{tabular}

Integration of UDL. The participants comfortably and frequently used the language of the UDL principles in their interviews - multiple means of representation, engagement, and expression - as they shared examples of how they integrated UDL into their lessons. There 
was an emphasis on being more "hands on" and on adapting materials to make them more multi-sensory. One participant reported using netbooks for students to do pre-research that prepared them to more effectively receive and take action on content presented in subsequent lessons and activities. Another described using the interactive features of SMART Notebook software (e.g., Vortex and Pull Tabs) to increase student engagement. One collaborative team integrated a play performance using BIGmack communication devices for nonverbal students to have speaking roles to express their learning. Another used "Stories in a Box" to add tactile elements and make other adaptations to make curriculum accessible to all. Others shared technology integration examples that included technology such as PREZI presentation software, Glogster multimedia posters, Wordle world clouds, video, projects and posters, document camera use, Internet flashcards, and gaming formats to show how the principles of UDL could be applied.

Current Supports. When asked what types of supports participants now have in place to integrate UDL, the themes of school or county instructional technology assistance, technology on-site, and professional development with examples surfaced. Participants gained an awareness of more of the resources and supports in the county, including the university AT lab and the professional development facilitators. Several mentioned the school-based technology teachers were helpful. Two general education participants felt the special educators had a slight advantage over the general educators in access to AT and supports. However, during the study, they learned that there is a new county AT Lab and AT webpage that has houses all the resources; and they now realize all teachers can all access these resources. One team of participants shared that their principal provides great support by protecting the class size of the general education class because of the inclusion co-teaching model.

Participants also appreciated receiving the technology tools with training and demonstrations. One participant noted that they received the tools, but also got the demonstrations and how to use them. The realization that there are supports within the county was probably best summarized by this participant's response:

In my eleven years of teaching, there has not been a collaborative effort or anything else that I have gone to since I have been teaching where I have sat in a room full of my peers like we did at East Carolina [University] and have people just go, "Wow...wow...wow." And it is everybody in the study-because everybody has their own twist, their own perspective on how they are doing things, and I don't think anybody is doing it the same. But the outcomes are the same- the outcomes are student success.

Challenges. The key theme for the topic of challenges was clearly the time factor. The participants repeatedly expressed that the lack of work days, larger caseloads, and added demands on teachers in general make it difficult to be flexible, creative, and learn new things. Some felt time was also needed to make adapted materials in order to be inclusive for all. The professional development provided by this training, however, appeared to help with this aspect of time. As one participant stated,

You want to use it all, but you don't have the time to learn it and how to integratenot a bad problem to have, though. The training helped me learn some things faster than I would have been able to do on my own. 
Along the same line, another participant voiced another realization about applying UDL principles as she goes along to improve her practice:

You know how sometimes you get information that is so much that you can't absorb it at the time, and when summer comes you are worn out. But it's just a matter of being able to take what I have and figure out how to apply it to my classes.

Other challenges mentioned were a lack of funding, anxiety about learning a new technology, coming up with ideas for students with more significant needs (i.e., nonreaders, difficult behaviors). However, the participants voiced appreciation for the grant funding aspect of this project for technology and training they received. They felt this kind of staff development alleviated some of the anxiety they often feel when learning new skills and technologies: "Doing the UDL training, even though I knew it was possible, it helped me to understand that it's a lot more possible than you think."

Needed Support/Resources. The themes time and training with supports surfaced again when participants were asked what would help them more fully integrate UDL. Participants expressed that they would like ongoing specific training sessions, such as those provided through the scope of this study, and time to prepare and implement what was learned. One participant mentioned the desire to have time to visit other classrooms where UDL is modelled and integrated well. Participants would also like to have more ways of sharing ideas - perhaps through weekly video blogs that could be easily accessed during school hours.

Having access to more low-tech items, as well as time to learn about them, was also mentioned. One participant described how a school computer lab and other shared school technology can be a barrier:

Computer lab use is specific to certain programs, so that isn't a great resource. Classes have to schedule time in the lab for very specific things. Things like iPods/iPads are in high demand so you may only be able to get them a few times throughout the year.

Another participant also expressed more feelings of anxiety related to time: "Sometimes it feels overwhelming [because] it does take a lot of time to think about each individual student and try to individualize instruction." Overall, participants recognized the need for time to learn and process the technologies and skills needed to implement the UDL principles in their classrooms. They saw the benefits of taking it one step at a time: "It takes a lot of time, but I think if you put the time in, in the long run, it's worth it. So what I'm trying to do this year is to learn the smart board. [I'm] trying to do something new, a little at a time, ongoing."

\section{Conclusions}

Perceptions and conceptualizations of UDL, implementation of UDL principles in the classroom, and how to use technology appropriately and effectively to support UDL increased across the board for all participants and settings. As indicated on the pre- and post-test surveys, the highest percentages of change among the participants were three (out of four) of those in the inclusion classes with overall gains of 56-96\%. The fourth inclusion class (Middle School Inclusion 1) had relatively high pre scores in both the technology and UDL sections, which logically resulted in a lower gain overall. Based on post-study interview responses, having a co-teaching partner to help with integrating 
UDL principles in planning and technology integration made it easier for those in inclusive settings to engage in new teaching practices. Compared to those in adapted settings, who typically plan and teach alone, the co-teaching model appears to offer builtin supports and resources for teachers learning how to apply UDL principles and learning new technologies, making it easier to move forward with changes to teaching practices.

Participants in self-contained settings had higher pre scores in the area of technology, but had relatively lower pre scores on UDL. Their post scores in UDL demonstrate higher increases in their understandings and implementation of UDL, with overall percentage gains in the $31-40 \%$ range. This may be due to the fact that self-contained adapted curriculum settings typically have more diverse student needs due to more significant disabilities: As compared to general education inclusive settings, such adapted settings typically require more differentiation, more planning, and more training to be able to work with students who rely on technology for basic functional needs such as communication.

While the results of this study cannot be generalized due to the small number of participants, the trends found in these results are promising in demonstrating that the UDL framework and infusion of technology, along with adequate support and training during implementation, result in instructional practices that are more inclusive of all diverse learners across educational settings. When offered the time and resources for training and planning, teachers can, and will, shift their instructional practices to reflect universally designed instructional settings that will likely better meet the needs of their students. The next step in determining whether the integration of UDL principles and the use of technology tools that support instruction for diverse learners indeed constitute a best practice is to measure student achievement, comparing the performance of students in instructional settings that align with the UDL framework with the performance of students in settings that do not embrace UDL principles. This will be difficult to measure due to a plethora of variables that impact student achievement. In support of UDL as an effective instructional framework, this study's results add to the evidence that through the use of UDL principles, in tandem with appropriate learning strategies and instructional technology tools with supports, teachers increase their provision of multiple representation, engagement, and expression elements in their instruction. This change in pedagogy supports the premise that increased engagement of learners with instructional practices leads to increased student achievement (Bundick, Quaglia, Corso, \& Haywood, 2014).

\section{References}

Alnahdi, G. (2014). Assistive technology in special education and the universal design for learning. Turkish Online Journal of Educational Technology, 13(2), 18-23.

Bundick, M., Quaglia, R., Corso, M., \& Haywood, D. (2014). Promoting student engagement in the classroom. Teachers College Record, 116(4), 1-34.

Center for Applied Special Technology (CAST). (2011). UDL guidelines-Educator checklist version 2. Wakefield, MA: Author

Center for Applied Special Technology (CAST). (2015). About UDL: What is universal design for learning? Wakefield, MA: Author.

Center for Universal Design. (2008). About the Center: Ronald L. Mace. Retrieved from https://www.ncsu edu/ncsu/design/cud/about_us/usronmace.htm 
Smith Canter, King, Williams, Metcalf, \& Potts

Darling-Hammond, L. (2006). Constructing 21st century teacher education. Journal of Teacher Education, 57(3), 300-314.

Demski, J. (2012). This time it's personal. T. H. E. Journal, 39(1), 32-36.

Edyburn, D. (2010). Would you recognize universal design for learning if you saw it? Ten propositions for new directions for the second decade of UDL. Learning Disability Quarterly, $33(1), 33-41$.

Edyburn, D., \& Gardner, J. (2009). Readings in special education technology: Universal design for learning. Arlington, VA: Council for Exceptional Children.

Fullan, M. (2010). All systems go: The change imperative for whole system reform. Thousand Oaks, CA: Corwin.

Garguilo, R., \& Metcalf, D. (2015). Teaching in today's inclusive classroom: A universal design for learning approach (3rd ed.). Belmont, CA: Wadsworth/Cengage Learning.

Hall, T., Meyer, A., \& Rose, D. (2012). Universal design for learning in the classroom: Practical applications. New York, NY: Guilford Press.

Hartmann, E. (2015). Universal design for learning (UDL) and learners with severe support needs. International Journal of Whole Schooling, 11(1), 54-67.

Hull, T., Balka, D., \& Miles, R. (2010). Overcoming resistance to change. Principal Leadership, $10(8), 36-37,40-42$.

Katz, J. (2015). Implementing the Three Block Model of universal design for learning: Effects on teachers' self-efficacy, stress, and job satisfaction in inclusive classrooms $\mathrm{K}-12$. International Journal of Inclusive Education, 19(1), 1-20.

Meyer, A., Rose, D. H., \& Gordon, D. (2014). Universal design for learning: Theory and practice. Wakefield, MA: CAST.

Patterson, C. (2010). On school reform: A history of resistance to change [Web log post]. Retrieved January 8, 2016, from http://learningshore.edublogs.org /2010/10/24/on-school-reform-a history of resistance to change/

Rose, D., \& Meyer, A. (2002). Teaching every student in the digital age. Alexandria, VA: Association for Supervision and Curriculum Development.

Stipek, D. (2002). Good instruction is motivating. In A. Wigfield \& J. Eccles (Eds.), Development of achievement motivation (pp. 310-330). San Diego, CA: Academic Press.

Thousand, J., Villa, R., \& Nevin, A. (2013). Differentiating instruction: Collaborative planning and teaching for universally designed learning (3rd ed.). Thousand Oaks, CA: Corwin Press.

\section{Disclosure}

The authors and their research programs are not in any way affiliated with or funded by the makers or distributors of any product named in this article. Brand names are reported only for the purpose of factual accuracy, and our use of such products for research purposes does not constitute an endorsement of any particular brand or vendor.

\section{Authors' Note}

Correspondence concerning this article should be addressed to Lora Lee Smith Canter, Special Education, Foundations, \& Research Department, College of Education, East Carolina University, Greenville, NC, 27858, USA. Email: smithcanteerl@ecu.edu 